\title{
Combined-hole film cooling with the application of double flow control devices
}

\author{
Haswira Hassan and Kamil Abdullah* \\ Faculty of Mechanical and Manufacturing Engineering, Universiti Tun Hussein Onn Malaysia \\ (UTHM), 86400 Parit Raja, Johor, Malaysia
}

\begin{abstract}
In the modern gas turbine, film cooling system was applied to the turbine blades to provide thermal protection from extreme turbine inlet temperatures. Recent literature discovers that adding the double flow control device (DFCD) and combining two cylindrical holes (combinedhole) are the ways to further enhance the film cooling performances. In the present simulation work, the influence of DFCD on the combined-hole film cooling was investigated at different blowing ratios. The comparison between two different computational domains of combined-hole film cooling with and without DFCD was further discussed in the present work. The results show that increase the blowing ratio, $\mathrm{M}$ rise the overall performance of combined-hole film cooling with and without DFCD. Based on the different computational domain, combined-hole with DFCD has better lateral spread at $\mathrm{M}=0.5$ and $\mathrm{M}=0.75$ in comparison with the combined-hole without DFCD. However, due to large counter clockwise vortex produced by the combined-hole with DFCD, unsymmetrical film cooling coverage was formed along the streamwise direction at $\mathrm{M}=1.0$ and $\mathrm{M}=1.5$. As the conclusion, combined-hole film cooling with DFCD has better performance at $\mathrm{M}=0.5$ and $\mathrm{M}=0.75$ while combined-hole film cooling without DFCD has better performance at high blowing ratio of $\mathrm{M}$ $=1.0$ and $\mathrm{M}=1.5$.
\end{abstract}

\section{Introduction}

The performance of the gas turbines can be improved with the increased of the turbine inlet temperature. Due to high turbine inlet temperature, very effective cooling techniques are required to protect the turbine components which exposed to extreme thermal loads to which also jeopardising its durability. Film cooling system was introduced especially on the turbine blades to provide enhance thermal protection and ensure its reliability. Film cooling provides external protection of the blade surfaces with formation of thin layer of cooled air. The cooled air which provided by the compressor bleed through the cooling holes and prevents the direct contact between the hot mainstream gases with the blade surfaces thus ensure lower temperature and heat transfer on the turbine blades. Goldstein [1], among the pioneers in the field has provided the fundamental understanding of film cooling. 
Cylindrical film cooling hole has been introduced as basic geometry of the cooling hole and still being applied in modern gas turbine due to its simplicity, low maintenance and manufacturability. Several studies [2-4] were carried out and described the film cooling mechanism of the cylindrical film cooling hole. All the early studies agreed on the existence of kidney vortex in cylindrical film cooling hole system. The vortices stated to contribute to narrow coverage and degrading of the film cooling effectiveness. One of the effectiveness way to control the formation of the kidney vortex and improve the film cooling effect is by adding devices upstream or downstream of the cooling holes and changing the geometry of film cooling hole. Takisawa et al. [5] and Kawabata et al. [6] added the flow control devices upstream of the cylindrical film cooling hole which been reported to altered the formation of the kidney vortex while improving the film cooling performance. Meanwhile, other the research [7-9] have also reported improvement on the film cooling performance through combined-hole configuration which is achieved by combining two film cooling holes together as a unit. The combined-hole film cooling produced an anti-kidney vortex and keeps the cooling gas attached to the wall. The present work is aim to observe the influence of the flow controlling devices on the performance of the combined-hole film cooling at different blowing ratio.

\section{Methodology}

\subsection{Computational domain and validation}

The computational domain in the present study combined two main sections of mainstream and cooling gas duct embedded with the combined-hole film cooling. Basically, two computational domains have been considered; a) without Double Flow Control Devices (DFCD), and b) with Double Flow Control Devices (DFCD). Fig. 1 shows the dimensions of the computational domain with the value of $\mathrm{D}$ was based on the hole diameter which is equal to $3 \mathrm{~mm}$. Table 1 and Fig. 2 indicate the details on the combined-hole and DFCD applied in the present study and the origin was located at the middle between two centres of the combined-hole film cooling. The dimensions of computational domain and combinedhole film cooling were based on the research of Hassan and Abdullah [10] and the dimensions of DFCD was based on the research of Takisawa [5].

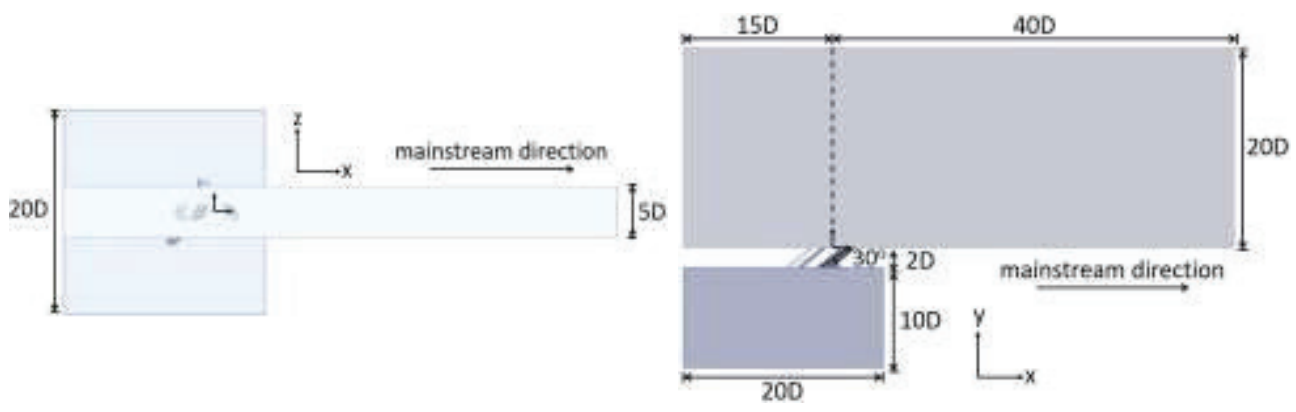

Fig. 1. Dimensions of the computational domain [10]

Table 1. Dimensions of the DFCD and combined-hole film cooling. [5, 10]

\begin{tabular}{|l|l|l|l|l|l|l|l|l|}
\hline A & B & C & D & E & F & G & H & J \\
\hline
\end{tabular}




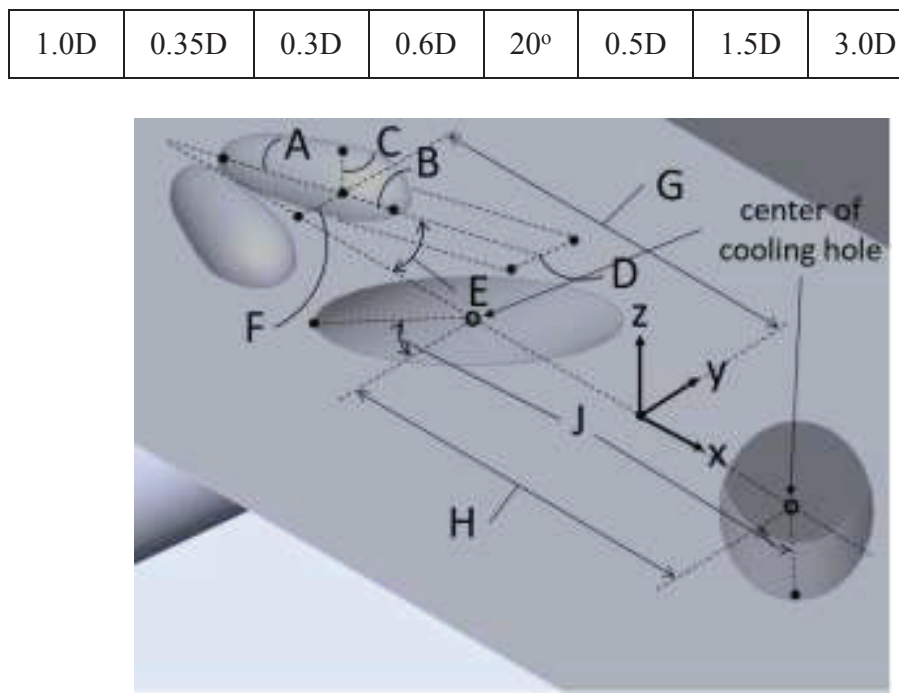

Fig. 2. Details on the DFCD and combined-hole film cooling $[5,10]$

\subsection{Numerical setup}

Fig. 3 shows the boundary conditions on the computational domain of the present study. ANSYS CFX software involving steady state Reynolds Average Navier Stokes (RANS) analysis with the employment of Shear Stress Transport (SST) turbulence model was applied on the present study. The boundary conditions applied in the present study are similar to the work of Hassan and Abdullah [10]. Table 2 shows the flow conditions applied in the present study. The mass flow rate of the cooling gas for the combined-hole has been determined with the assumption that both cooling holes are operating at the same blowing ratio and the sum of the required mass flow rate of each hole has been applied at the cooling gas inlet of the computational domain.

Table 2. Flow conditions.

\begin{tabular}{|c|c|}
\hline Reynold's Number, Re ${ }_{\mathrm{D}}$ & 4200 \\
\hline Mainstream Velocity, $\mathrm{U}_{\infty}$ & $22.065 \mathrm{~m} / \mathrm{s}$ \\
\hline Mainstream Temp., $\mathrm{T}_{\infty}$ & $300 \mathrm{~K}$ \\
\hline $\begin{array}{c}\text { Mainstream Turbulent. } \\
\text { Intensity, Tu }\end{array}$ & $6 \%$ \\
\hline Blowing Ratio, $\mathrm{M}$ & $0.5,1.0,1.5$ \\
\hline Cooling Gas Inlet Temp., $\mathrm{T}_{\mathrm{c}}$ & $310 \mathrm{~K}$ \\
\hline
\end{tabular}




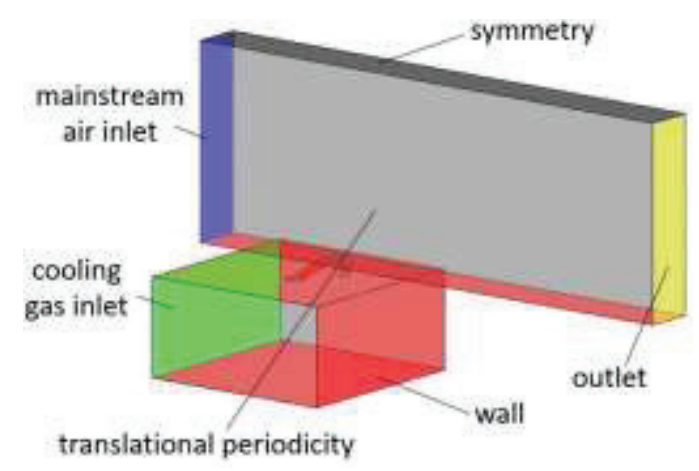

Fig. 3. Boundary conditions

\subsection{Mesh dependency test and validation}

Fig. 4 shows the lateral average film cooling effectiveness results of the mesh dependency test conducted at $\mathrm{M}=0.5$ with the use of hybrid meshing. The medium mesh with approximately 8.2 million nodes was applied to each case to minimize discretization error and computational time. Besides that, Fig. 4 also shows the validation between the numerical results of the present study with the experimental results of previous research reported by Han et al. [11]. The lateral results show good agreement along the streamwise direction. However, such divergent of the result might be caused by the incapability of the turbulent model to accurately predict the interaction of the mainstream air and the cooling air.

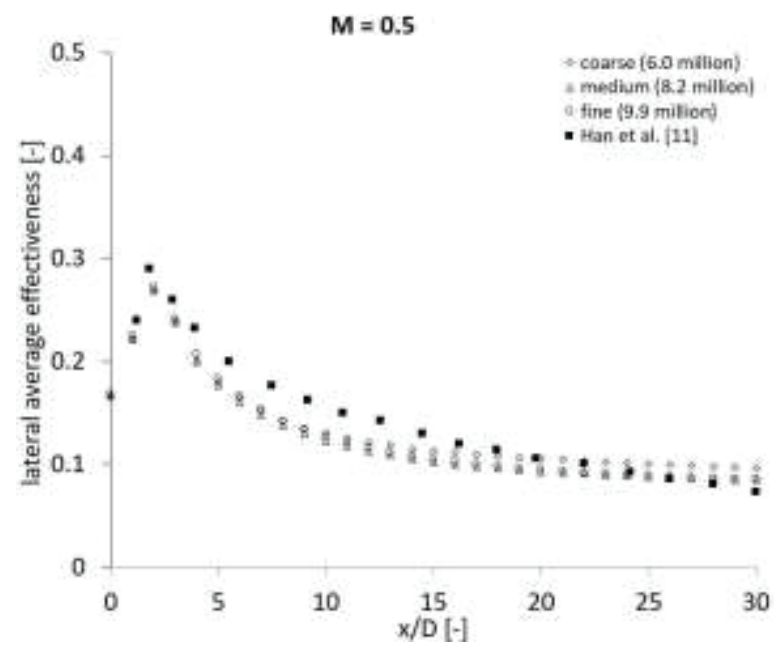

Fig. 4. Mesh dependency test and validation with the previous research

\section{Results and discussion}

Fig. 5 shows the film cooling effectiveness distributions for all considered cases. Based on figure, the film cooling effectiveness was completely altered with the application of DFCD at different blowing ratios. At $\mathrm{M}=0.5$, combined-hole with DFCD shows significant change with slightly wideer coverage of film cooling along the streamwise direction. The 
lateral coverage also enhanced as the blowing ratio increases in comparison with the $\mathrm{M}=$ 0.5 case.

Fig. 6 and 7 show the vorticity contours on yz planes at $x / D=5,10$ and 15 . In the case of combined-hole film cooling without DFCD, the kidney vortex was observed at the early downstream and reduced along the streamwise direction. In addition, increase the blowing ratio on the combined-hole film cooling without DFCD increase the size of kidney vortex. In the case of combined-hole film cooling with DFCD, an additional counter clockwise vortex was produced in early downstream at $\mathrm{M}=0.5$ and $\mathrm{M}=0.75$ which was preserved until $x / D=15$ as shown in Fig. 6 . Differed with the cases of $M=1.0$ and $M=1.5$, there are no sign of additional vortex is observed. However, in comparison with the case of $\mathrm{M}=0.5$ and 0.7 , the size of the kidney vortex was further enhanced in the case of $M=1.0$ and $\mathrm{M}=$ 1.5 .

Based on Fig. 5 - 7, the application of DFCD on the combined-hole film cooling totally change the flow structure along the streamwise direction thus significantly influence the film cooling effectiveness. An additional counter clockwise vortex produces in the case of $\mathrm{M}=0.5$ and $\mathrm{M}=0.75$ with $\mathrm{DFCD}$ enhanced the film cooling coverage on the positive side of the z-axis. Besides that, improvement can also be observed at near cooling hole region in the case of $\mathrm{M}=0.75$ and $\mathrm{M}=1.0$ with $\mathrm{DFCD}$. This is due to altered flow structure at early downstream. However, the cooling gas from both cooling holes tend to flow in their own path and produced a small area of low film cooling effectiveness from $x / D=4$ to $x / D=8$ in the case of $\mathrm{M}=0.75$ and $\mathrm{M}=1.0$ with DFCD. In addition, the large size of counter clockwise vortex observed at the early downstream region formed the unsymmetrical film cooling coverage which is preserved further downstream as shown in Fig. 5.

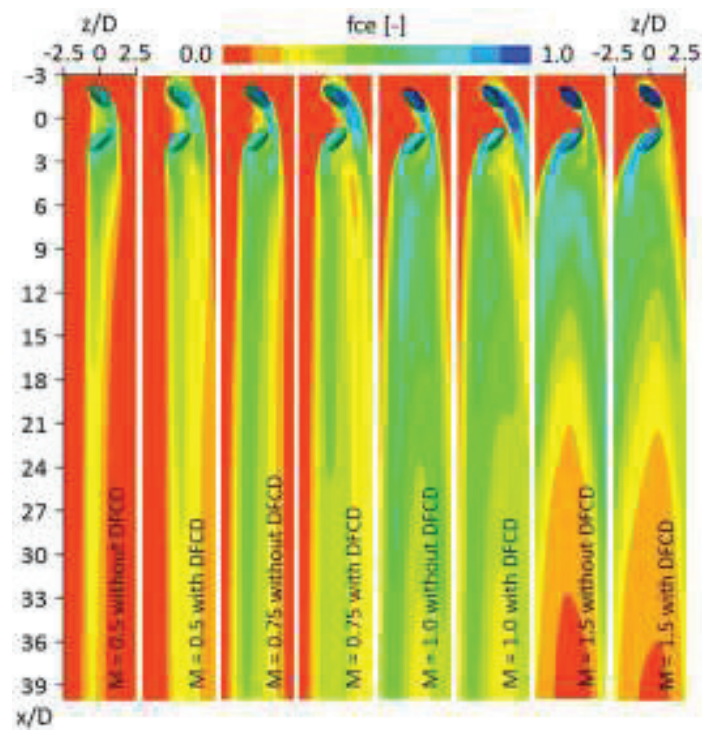

Fig. 5. Film cooling effectiveness distributions 


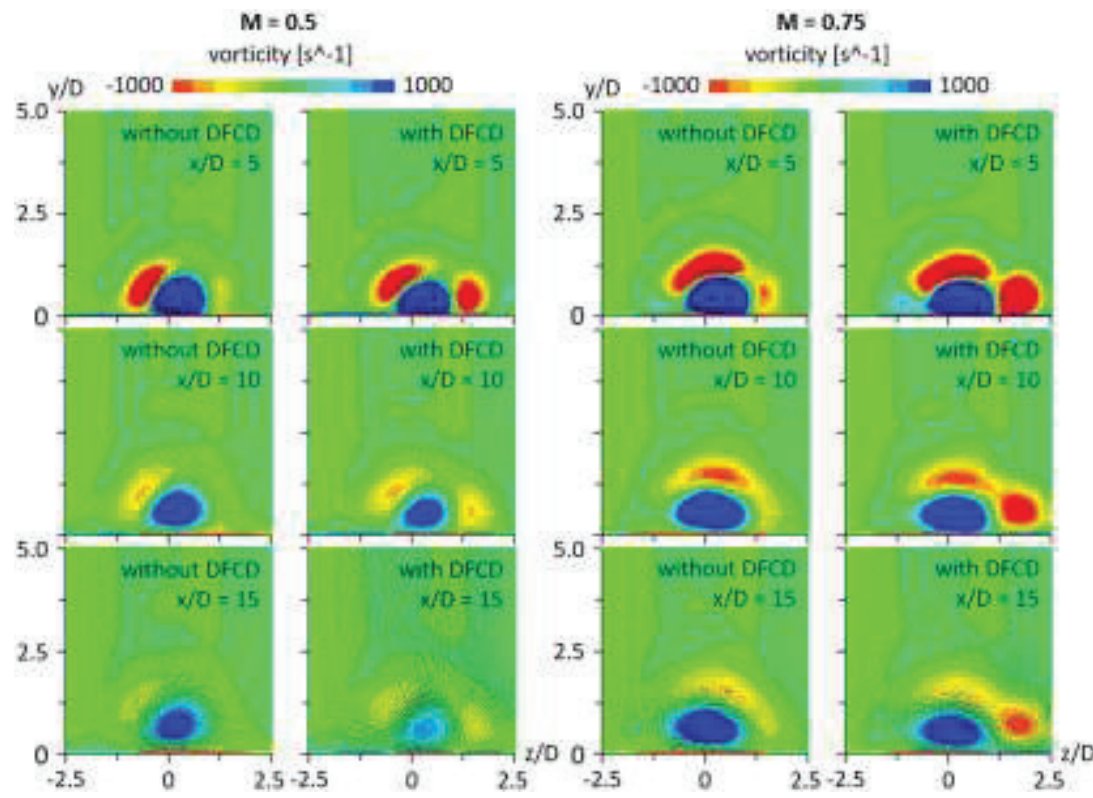

Fig. 6. Vorticity at $M=0.5$ and $M=0.75$
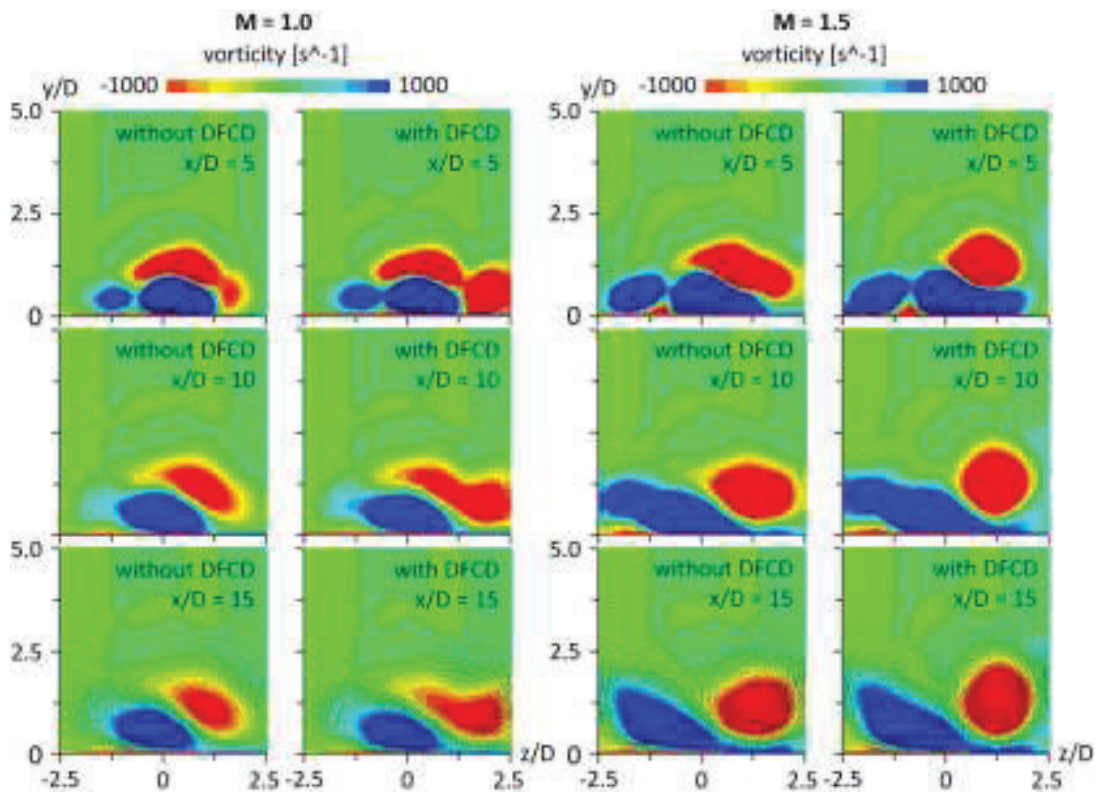

Fig. 7. Vorticity at $\mathrm{M}=1.0$ and $\mathrm{M}=1.5$

Fig. 8 shows the lateral average film cooling effectiveness graph for all considered cases. The performance of combined-hole film cooling with and without DFCD was increased as the blowing ratio increase until $\mathrm{M}=1.0$. However, the performance of combined-hole in the case of $\mathrm{M}=1.5$ is better at early downstream and reduced further downstream. At $\mathrm{M}=0.5$ and $\mathrm{M}=0.75$ cases, the combined-hole film cooling with DFCD has better lateral average film cooling effectiveness due to wide film cooling coverage as shown in Fig. 5. Meanwhile, the combined-hole film cooling without DFCD has better lateral average film cooling effectiveness in comparison with the combined-hole with 
DFCD in the case of $\mathrm{M}=1.0$ and $\mathrm{M}=1.5$ due to narrow and unsymmetrical film cooling coverage along the streamwise direction.

Fig. 9 shows the area average film cooling effectiveness that generally evaluates the film cooling effect at different cases. The width of the area is the pitch of the combinedhole, $5 \mathrm{D}$ and the length is from $\mathrm{x} / \mathrm{D}=0$ to $\mathrm{x} / \mathrm{D}=40 \mathrm{D}$. At $\mathrm{M}=0.5$ and $\mathrm{M}=0.75$, combinedhole film cooling with the application of DFCD have better area average film cooling effectiveness compared to the combined-hole film cooling without DFCD. Meanwhile, combined-hole without DFCD configurations have better performance than combined-hole film cooling with DFCD.

In the case of $\mathrm{M}=1.5$ with $\mathrm{DFCD}$, narrow coverage of film cooling effectiveness was observed in the early downstream due to the formation of counter clockwise vortex. The formation of the vortices in the case of $\mathrm{M}=1.5$ without DFCD covering the lateral direction along the streamwise direction which formed the wide coverage of film cooling effectiveness as shown in Fig. 5. Meanwhile, in the case of $M=1.5$ with DFCD, the formation of vortices only covering the lateral direction until $\mathrm{z} / \mathrm{D}=2.0$ as shown in Fig. 7 and consequently produce narrow coverage of film cooling effectiveness from $\mathrm{x} / \mathrm{D}=2$ to $\mathrm{x} / \mathrm{D}=12$ and unsymmetrical film cooling coverage further downstream as shown in Fig. 5.

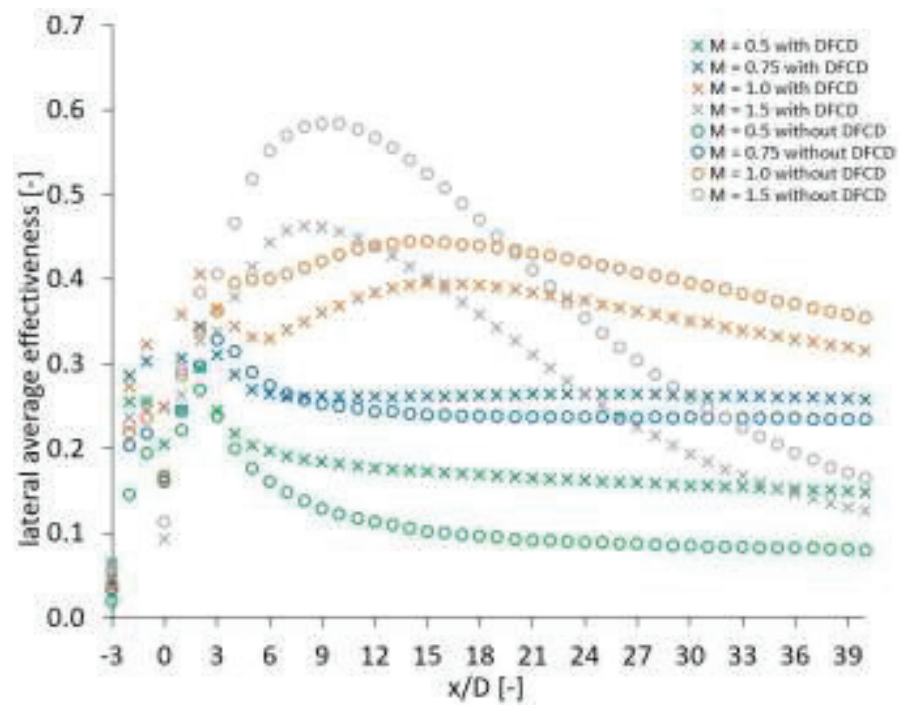

Fig. 8. Lateral average film cooling effectiveness graph 


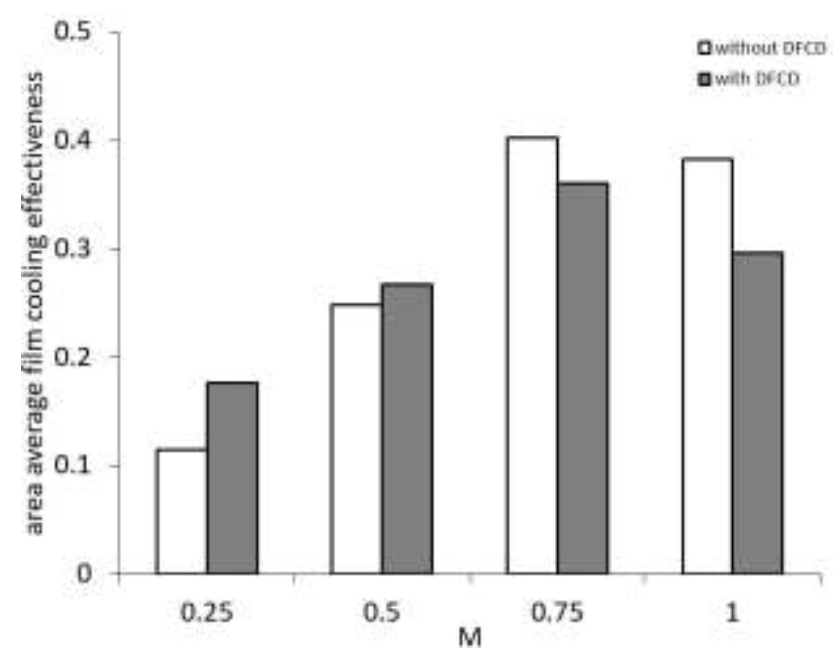

Fig. 9. Area average film cooling effectiveness graph

\section{Conclusions}

A batch of simulation focused on the application of DFCD on the combined-hole film cooling system had been carried out using steady state Reynolds Averaged Navier Stokes (RANS) method of ANSYS CFX, with Reynolds number, $\mathrm{Re}=4200$ at blowing ratios, $\mathrm{M}=$ $0.5,0.75,1.0$ and 1.5 . The conclusions for the present study are as follow:

- Increase the blowing ratio until $\mathrm{M}=1.0$ increase the overall film cooling performance. Meanwhile, increase the blowing ratio to $M=1.5$ reduce the overall performance in comparison with the results of $\mathrm{M}=1.0$ due to faster dissipation occurred.

- In the case of $\mathrm{M}=0.5$ and $\mathrm{M}=0.75$, the combined-hole film cooling with DFCD show better overall performance compared to the combined-hole film cooling without DFCD. The existence of DFCD altered the formation of vortices in these cases and produced better separation of cooling gas along streamwise direction.

- In the case of $\mathrm{M}=1.0$ and $\mathrm{M}=1.5$, the combined-hole film cooling without DFCD show better overall performance compared to the combined-hole film cooling with DFCD. The existence of DFCD produced larger counter clockwise vortex and drag the cooling gas to the positive side of $\mathrm{z}$-axis and formed unsymmetrical film cooling coverage alond streamwise direction.

\section{Acknowledgment}

The author would like to thank both Universiti Tun Hussien Onn Malaysia (UTHM) and Ministry of Higher Education of Malaysia for the financial support through Fundamentals Research Grant Scheme (Vot 1544).

\section{References}

1. R.J. Goldstein, Film cooling. Advances in heat transfer. 7, 321-379. (1971)

2. R.J. Goldstein, E.R.G Eckert, F. Burggraf. Effects of hole geometry and density on three-dimensional film cooling. International Journal of Heat and Mass Transfer. 17, 595-607. (1974) 
3. M. Gritsch, A. Schulz, S. Wittig. Film-cooling holes with expanded exits: nearhole heat transfer coefficients. International Journal of Heat and Fluid Flow. 21, 146-155. (2000)

4. C. Han, J. Ren. Multi-parameter influence on combined-hole film cooling system. International Journal of Heat and Mass Transfer. 55, 4232-4240. (2012)

5. H. Takisawa, K.I. Funazaki, H. Sasaki, T. Kawamura, H. Tagawa, S. Nakano. Improvement of flat-plate film cooling performance by double flow control devices under high density ratio.

6. H. Kawabata, K.I. Funazaki, R. Nakata, D. Takahashi. Experimental and numerical investigations of effects of flow control devices upon flat-plate film cooling performance. Journal of Turbomachinery. 136. (2014)

7. K. Kusterer, D. Bohn, T. Sugimoto, R. Tanaka. Influence of blowing ratio on the double-jet ejection of cooling air. ASME Turbo Expo 2007: Power for Land, Sea, and Air. American Society of Mechanical Engineers. 305-315. (January, 2007)

8. K.D. Lee, D.W. Choi, K.Y. Kim. Optimization of ejection angles of double-jet filmcooling holes using RBNN model. International Journal of Thermal Sciences. 73,6978. (2013)

9. D.W. Choi, K.D. Lee, K.Y. Kim. Analysis and optimization of double-jet film-cooling holes. Journal of Thermophysics and Heat Transfer. 27, 246-254. (2013)

10. H. Hassan, K. Abdullah. Effect of symmetrical compound-angle in combined-hole film cooling. (2006)

11. C. Han, Z. Chi, J. Ren, H. Jiang. Optimal arrangement of combined-hole for improving film cooling effectiveness. Journal of Thermal Science and Engineering Applications. (2015) 